\title{
SAR News
}

\section{William W. Mayo-Smith}

Brown University/Rhode Island Hospital, 593 Eddy St., Providence, RI 02903, USA

Welcome to the Society of Abdominal Radiology (SAR) News section of the journal of Abdominal Imaging. This new section will be a regular feature in Abdominal Imaging with the purpose of updating the membership and all radiologists on the latest developments within the SAR. Where to begin? The SAR is in its second year, formed from the merger of the Society of Gastrointestinal Radiologists and the Society of Uroradiology in 2012. The rationale and history behind the merger are well described in the Commentary published in Radiology by SAR inaugural President, Stuart Silverman [1]. The SAR, as a single source, hopes to meet the needs of all abdominal radiologists, and membership is open to all practicing radiologists.

The first SAR Scientific Meeting and Educational Course (also referred to herein as the "Annual Meeting") was held in March 2013 and was a tremendous success. The highlights of the Scientific Meeting portion were published in the November issue of Abdominal Imaging [2]. The second SAR Annual Scientific Meeting and Educational Course will be held in conjunction with the European Society of Urogenital Radiology in Boca Raton, Florida from March 23-28, 2014. The scientific session is on Sunday followed by multiple plenary sessions and 195 workshops covering all aspects of abdominal radiology. A special focus of the plenary sessions will be on value-added in radiology and quality and safety measures. Up to 38 category $1 \mathrm{CME}$ credits can be obtained from the meeting that features 290 speakers from 15 countries! A copy of the program and registration material can be found on the newly formed SAR website www.abdominalradiology.org.

The new and continuously developing SAR website outlines our mission, history, leadership, and the numerous committees that advance the scientific and educational charges of the Society. We encourage readers to visit the website to learn about our vibrant Society, and for non-members, the opportunity to join the SAR (applications are on the website). Benefits of membership include discounted rates to the Annual Meeting and an electronic subscription to this journal, Abdominal Imaging. You can also follow the SAR on Twitter(@SocAbdRadiology) and Facebook (Society of Abdominal Radiology) where we currently have over 2,500 "likes." The Facebook page includes the fun "Gettable Case of the Week" contests where you can post your answers, interact with colleagues, and receive tips from the experts.

In future journal issues we will go into more depth on different aspects of the SAR including specific committees and programs, such as the visiting professor programs. The goal of our newly-formed Society, now with its own journal and a new Editor, is to provide a onestop site for all abdominal radiologists to obtain scientific and educational content as it relates to the most current practice of abdominal radiology. We encourage your input and suggestions for topics of interest for our readership. Welcome and please join our new and exciting venture!

\section{References}

1. Silverman SG (2012) Society of abdominal radiology is created by a merger of the society of gastrointestinal radiologists and the society of uroradiology: form follows function. Radiology 265:336-338

2. Lambert DL (2013) Highlights from the scientific abstracts presented at the society of abdominal radiology 2013 annual scientific meeting and postgraduate course. Abdom Imaging 38:1185-1189 